\title{
Passive and Portable Polymer Optical Fiber Cleaver
}

\author{
Saez-Rodriguez, D.; Min, R.; Ortega, B.; Nielsen, Kristian; Webb, David J
}

Published in:

I E E E Photonics Technology Letters

Link to article, DOI:

10.1109/LPT.2016.2623419

Publication date:

2016

Document Version

Peer reviewed version

Link back to DTU Orbit

Citation (APA):

Saez-Rodriguez, D., Min, R., Ortega, B., Nielsen, K., \& Webb, D. J. (2016). Passive and Portable Polymer Optical Fiber Cleaver. I E E E Photonics Technology Letters, 28(24), 2834-2837.

https://doi.org/10.1109/LPT.2016.2623419

\section{General rights}

Copyright and moral rights for the publications made accessible in the public portal are retained by the authors and/or other copyright owners and it is a condition of accessing publications that users recognise and abide by the legal requirements associated with these rights.

- Users may download and print one copy of any publication from the public portal for the purpose of private study or research.

- You may not further distribute the material or use it for any profit-making activity or commercial gain

- You may freely distribute the URL identifying the publication in the public portal

If you believe that this document breaches copyright please contact us providing details, and we will remove access to the work immediately and investigate your claim 
Document downloaded from:

http://hdl.handle.net/10251/85140

This paper must be cited as:

D. Sáez-Rodriguez; Min, R.; Ortega Tamarit, B.; Nielsen, K.; Webb, D. (2016). Passive and Portable Polymer Optical Fiber Cleaver. IEEE Photonics Technology Letters. 28(24):28342837. doi:10.1109/LPT.2016.2623419.

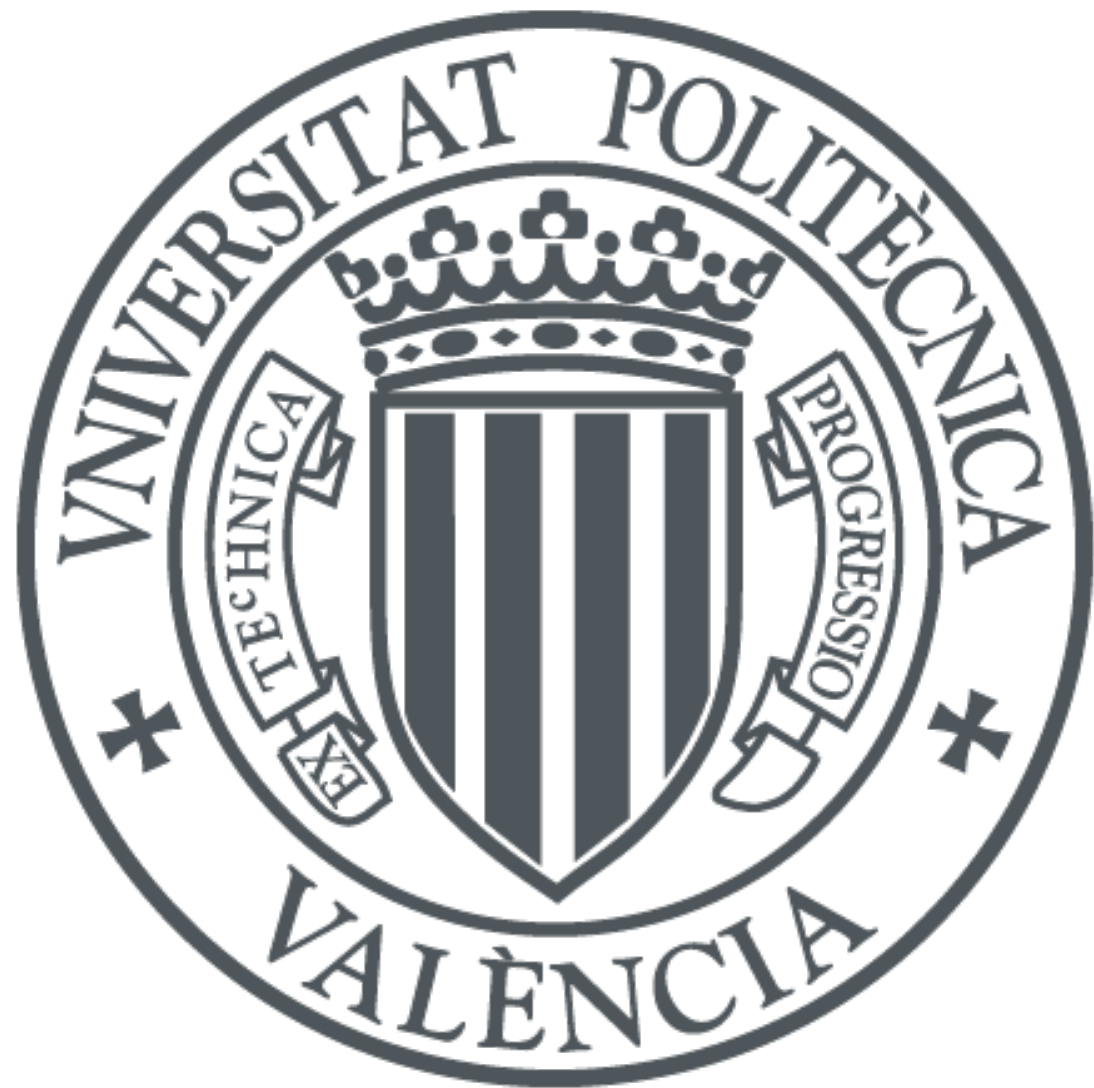

The final publication is available at

http://doi.org/10.1109/LPT.2016.2623419

Copyright Institute of Electrical and Electronics Engineers (IEEE)

Additional Information

"(c) 2016 IEEE. Personal use of this material is permitted. Permission from IEEE must be obtained for all other users, including reprinting/ republishing this material for advertising or promotional purposes, creating new collective works for resale or redistribution to servers or lists, or reuse of any copyrighted components of this work in other works." 


\title{
Passive and Portable Polymer Optical Fiber Cleaver
}

\author{
D. Sáez-Rodríguez ${ }^{1}$, R.Min $^{1}$, B.Ortega ${ }^{1}$, K.Nielsen $^{2}$, D.J. Webb ${ }^{3}$
}

\begin{abstract}
Polymer optical fiber (POF) is a growing technology in short distance telecommunication due to its flexibility, easy connectorization, and lower cost than the mostly deployed silica optical fiber (SOF) technology. Microstructured POFs (mPOFs) have particular promising potential applications in the sensors and telecommunications field, they could specially help to reduce losses in polymer fibers by using hollow-core fibers or reduce the modal dispersion by providing a large mode area endlessly singlemode. However, mPOFs are intrinsically more difficult to cut due to the cladding hole structure and it becomes necessary to have a high quality POF cleaver. In the well-known hot-blade cutting process, fiber and blade are heated, which requires electrical components and increases cost. A new method has recently been identified, allowing POF to be cut without the need for heating the blade and fiber, thus opening up the possibility of an electrically passive cleaver. In this paper, we describe the implementation and testing of a high quality cleaver based on a mechanical system formed by a constant force spring and a damper, which leads to the firstly reported electrical passive and portable cleaver.
\end{abstract}

Index Terms - Optical fibers, polymer optical fiber, polymer optical cleaver,POF,mPOF.

\section{INTRODUCTION}

$\mathrm{P}$ hotonic crystal fibers (PCFs) are single material fibers with a specific hole pattern in the cladding to allow guidance

of light; the first example was made by Knight et. al. in 1996 [1]. The design flexibility allowed by the microstructured geometry allows the manufacture of fibers with properties unachievable with step-index fibers, such as air guidance [2], endlessly single mode operation [3], larger or smaller modal area $[4,5]$, etc., which suggest a variety of applications including fiber lasers, nonlinear active fibers and biological sensing [6].

Polymer optical fiber (POF) technology has advanced rapidly in recent years and it is expected that it will form an integral part of datacom networks. They offer a broader bandwidth and easier installation for copper cables replacement [7]. In contrast

Manuscript received -,-; revised-,-; accepted -,-. Date of publication -,-; date of current version -, -. This work was supported by Juan de la Cierva Program of the Spanish Government and by the National project MINECO TEC201460378-C2-1-R MEMES and the Regional GVA funded PROMETEO 2013/012 project on Next Generation Microwave Photonic Technologies. We also acknowledge the support of the China Scholarship Council. We are very grateful to Professor Ole Bang to allow us to fabricate the fiber in the facilities of DTU.

${ }^{1}$ D. Sáez-Rodríguez, R.Min and B.Ortega are with the Institute of Telecommunications and Multimedia Applications (ITEAM) at Universidad to glass optical fibers, larger diameter POFs will remain mechanically flexible, which, in combination with a large core, offers easy and inexpensive connectivity of fibers during installation. Despite these achievements, POF has not yet achieved widespread deployment; mainly due to technical reasons such as large modal dispersion as a consequence of multimode operation and the higher losses than silica fiber.

Polymer PCFs, commonly known as microstructured polymer optical fibers (mPOFs), were firstly made by M.A. Van Eijkelenborg et. al. in 2001 [8]. The variety of possibilities of $\mathrm{mPOF}$ can help to overcome the aforementioned problems. On the one hand, polymer hollow-core fiber can be implemented to reduce losses significantly; the first example of this kind of fiber was reported by Argyros et. al. [9] and according to their theoretical calculations losses can be as small as $50 \mathrm{~dB} / \mathrm{km}$ in PMMA based fibers[10], comparable to the CYTOP fibers [11]. Furthermore, fabricating a mPOF with proper control of the pitch and hole size in the hole array allows fibers with a large modal area working in single mode operation [4].

However, mPOF are intrinsically difficult to cleave due to the hole array, therefore present and future commercial applications will require the development of a portable highquality $\mathrm{mPOF}$ cleaver. So far, several methods have been implemented to cleave mPOF [12-17], but none of them is well suited to the creation of a portable device. In the most commonly used and effective approach, fiber and blade are heated close to the glass transition temperature of the polymer, and then the blade cleaves the fiber with a controlled speed $[13,14]$. This method requires the assembly of a mPOF cleaver with several electronic components (temperature and motor controller, heater, stepper motor, power supply) which makes it expensive and power consuming, so hardly portable for outdoor applications. Recently, we have published a new method to cleave mPOF [18] at room temperature. The method is based on the time-temperature equivalence principle of polymers [19] which allows the heating of the blade and fiber to be replaced by a slow cleave. In this method, an endface free of crazing is achieved by making the duration of the

Politécnica de Valencia, Valencia 46022, Spain (e-mails: dasaerod@upv.es, rumi@doctor.upv.es, bortega@dcom.upv.es).

${ }^{2}$ K.Nielsen is with the Photonik, Denmark Technical University, Copenaghen, 2800, Denmark.(e-mail: krini@fotonikdoctor.dtu.dk).

${ }^{3}$ D.J. Webb is with the School of Engineering and Applied Science, Aston University, Birmingham, West midlands B4 7ET, U.K. (e-mail: d.j.webb@aston.ac.uk). 
process of cleaving longer than a certain time, which is characteristic of each polymer. Allowing sufficient time for the cut enables to relax the stress in the cutting tip, and therefore, crazing is prevented.

Figure 1 shows the cleaver used in our previous work [18], where the fiber was sawed rather than chopped (we use the word chop to describe the case when the blade cuts the fiber by being moved in a direction at $90^{\circ}$ to the blade edge). In that cleaver, a translation stage was used to move the blade at different controlled constant velocities. The smaller the blade angle $\alpha$ (defined in Fig. 2) the higher the sawing time for a constant speed of the blade. However, high quality PMMA cleaving was accomplished with relatively high blade velocities $(0.1-1 \mathrm{~mm} / \mathrm{s})$ using blade angles from 1 to 5 degrees [18].

In this work, we present a high quality electrically passive and portable POF cleaver, where the correct range of velocities can be achieved by using a simple mechanical system composed of a constant force spring and a damper.

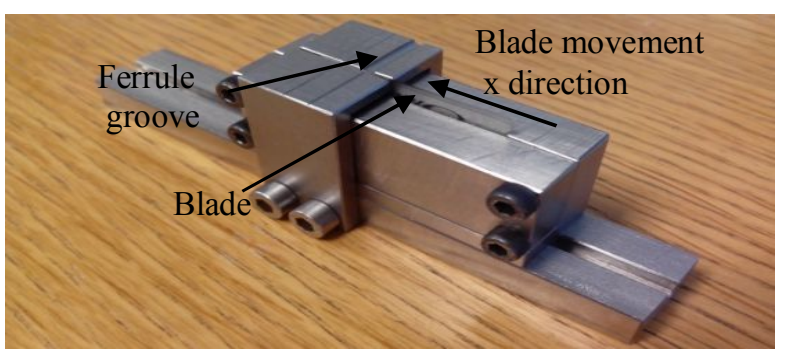

Fig. 1: Fiber and blade positioning in the $\mathrm{mPOF}$ cleaver earlier reported in [18]

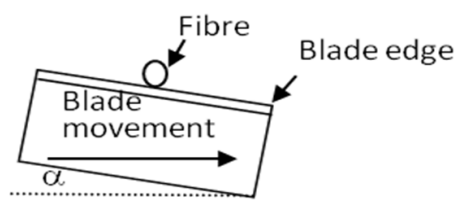

Fig. 2: Transversal view of the cleave process

\section{Cleaver Fabrication}

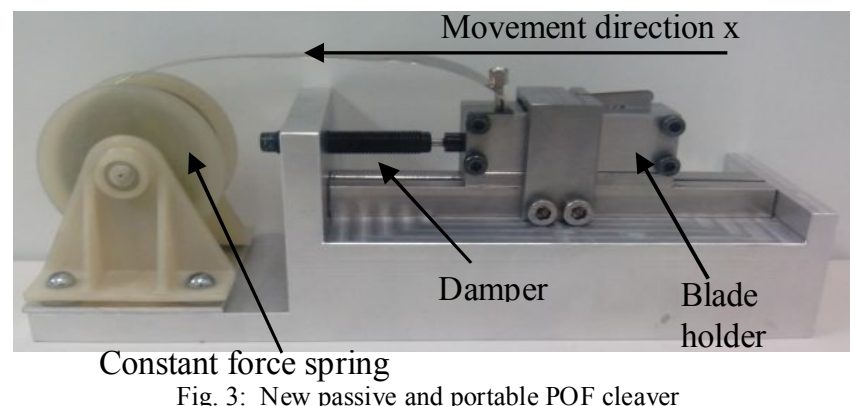

In order to implement the portable cleaver, a mechanical system composed of a constant force spring and a damper has been mounted, as showed in Fig. 3.

In Fig. 3, the constant force spring pulls the blade holder and the damper dampens this movement. The constantly damped mechanical system, according to the second Newton's law, can be described by the following inhomogeneous second order linear differential equation:

$$
\frac{d^{2} x}{d t^{2}}+\frac{b}{m} \cdot \frac{d x}{d t}-\frac{F_{S F}}{m}=0
$$

where $\mathrm{x}$ is the position of the blade along the movement direction, $F_{S F}$ is the difference between $F_{S}$ (spring force) and $F_{F}$ (friction force of the blade holder), $b$ is the damping coefficient of the spring, $\mathrm{t}$ is the time and $\mathrm{m}$ is the mass of the blade holder. The solution [20] of this equation gives the velocity of the blade as:

$$
v(t)=\frac{F_{S F}}{b} \cdot\left(1-e^{-\frac{b \cdot t}{m}}\right)
$$

where $v$ is the blade velocity. Using our system parameters, for times over a few milliseconds, $t>>\mathrm{m} / \mathrm{b}$, the velocity is approximately constant and is given by the following expression:

$$
v=\frac{F_{S F}}{b}
$$

The spring was provided by Spiroflex and pulls with a constant force of 7,8 N. The damper was provided by Ace Controls Inc (model HB-12-10) and according to our experiments the $b$ coefficient can be modified from 300 to $25000 \mathrm{~N} / \mathrm{m} / \mathrm{s}$. For the minimum value, the damper can travel over a distance of $7.5 \mathrm{~mm}$ while a length of $5 \mathrm{~mm}$ is covered when its maximum value is set.

Three minor additional modifications were done to improve the cleaving process. Firstly, the fiber being cleaved was only held from one side unlike [18] where it was clamped on both sides of the cutting point. Figure 4 shows both situations and typical results. In Fig. 4(a) the fiber is held from two sides and the fiber is sawed in the middle. This process creates axial stress in the fiber and consequently produces an end-facet with an endcrack, as can be seen in figure 4(c). This crack is observed in all the cuts in [18] and represents a region where part of the fiber has been torn away by the cleaving process. In contrast, in Fig. 4(b) the fiber is only held from one side avoiding such stress and therefore it is free of cracks, as shown in Fig. 4(d). Secondly, a new groove was included in the blade holder to allow cutting the fiber when it has been mounted inside a connector ferrule, as shown in Fig. 1. Finally, a modified blade with one almost flat-side, as shown in Fig. 5, is employed in the cleaver. The flat-side of the blade is placed as close as possible to the clamping point of the fiber in Fig. 4 (b) in order to increase the stiffness of the fiber section between the blade and the clamping point, as discussed in [18]. A flat-side blade was also earlier found to be optimal in the hot-blade cleaver in [14]. 
a)
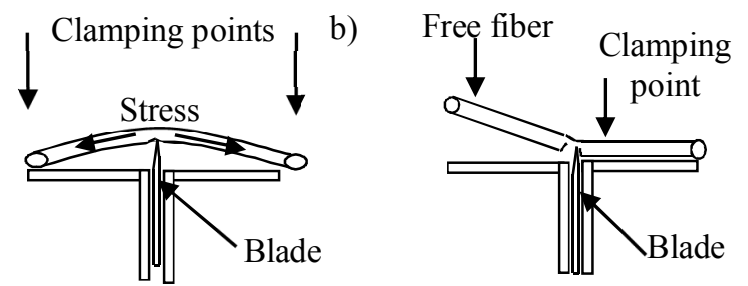

c)

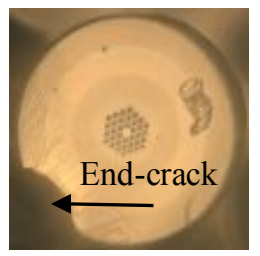

d)

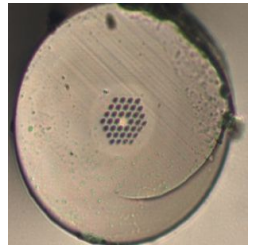

Fig. 4: (a) Schematic with two sides fiber holding. (b)Schematic with one side fiber holding. (c) End-face cleave using scheme (a). (d) Endface cleave using scheme (b).

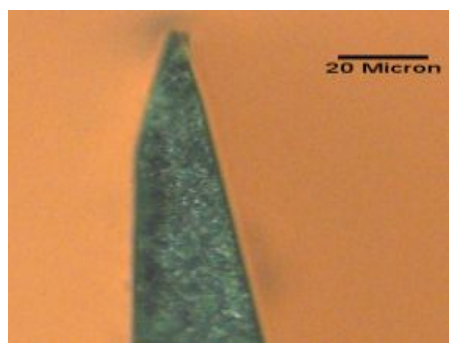

Fig. 5: Photograph of the blade tip

\section{CleAving DEMONSTRATION}

The cleaver has been characterized by using two different fibers, both fabricated at the Technical University of Denmark (DTU), with manufacturing detailed can be found in [18]. In table 1 and 2, the images corresponding to extreme sawing times are acquired by a scanning electron microscope (SEM) for the sake of higher resolution while the rest of the images are taken with an optical microscope.

Firstly, a three hole mPOF was used; this kind of fiber is rather hard to cleave due to the thin walls between holes and therefore is a good candidate for the cleaver test. Table 1 summarizes the results obtained for different angles and sawing times where such time is defined as the time the blade is cleaving the fiber. The results confirm that longer sawing times provide better end-faces of the fibers over the angle range reported in [18]. In this cleaver, the range of sawing times is limited by the damper velocity range.

Secondly, a three ring mPOF was used. In this case, an annealing process was necessary in order to relax the stress of the fabrication and therefore, clean end-faces can be obtained. Transversal sections of cleaved mPOFs are depicted in table 2 when un-annealed and annealed fibers are employed. The fiber annealing was done by introducing it in an oven over 24 hours at 70 degrees. The results showed that crazing in un-annealed fibers still remain for slow cutting times, whereas it disappears in the annealed fiber.

The proposed cleaver can be employed to cleave other structures and materials based on polymer fibers provided a

sawing time estimation work is done, similar to that presented in [18].

Table 1

TRANSVERSAL SECTION OF DIFFERENT CLEAVES (Three hole fiber).

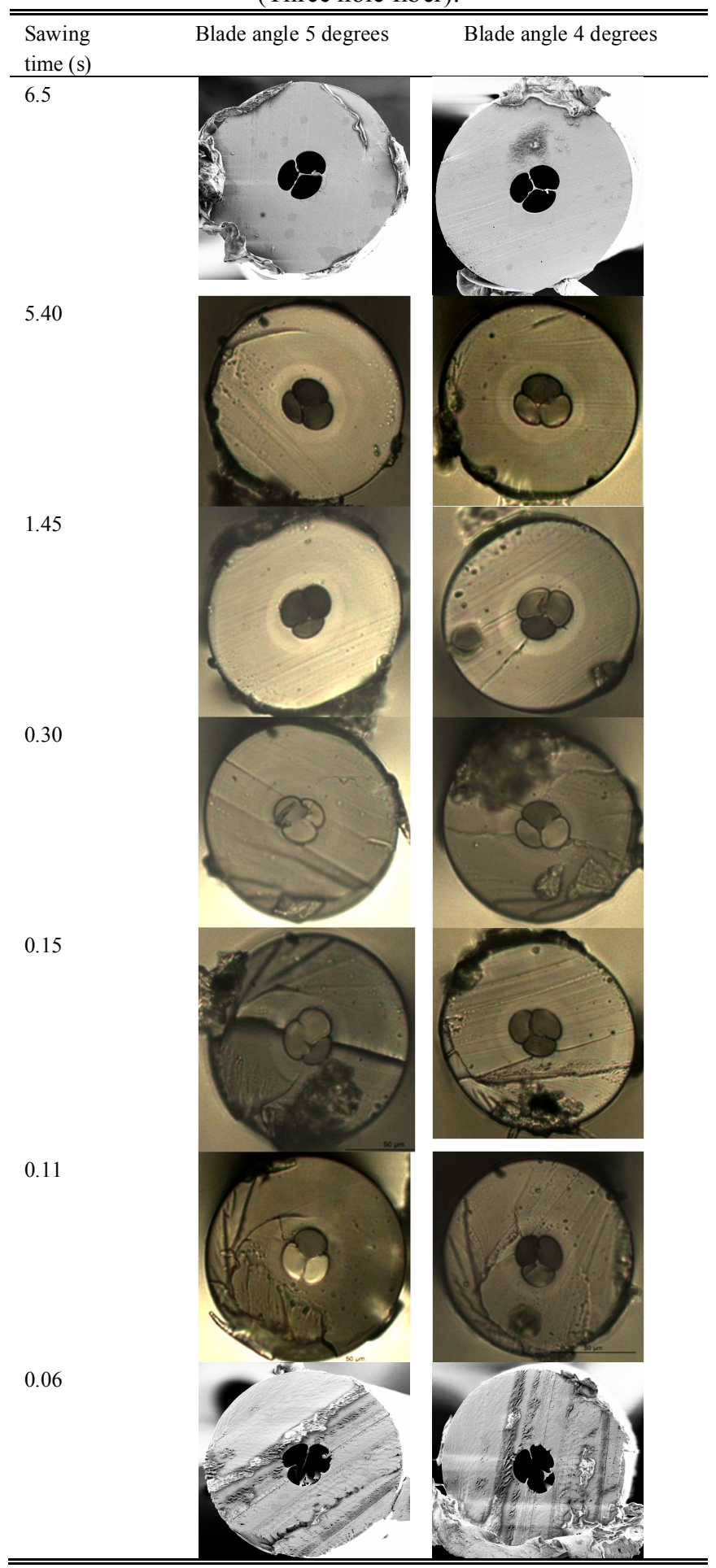


Table 2

TRANSVERSAL SECTION OF DIFFERENT
CLEAVES OF ANNEALED AND NOT
ANNEALED mPOF $\left(\alpha=5^{\circ}\right)$.

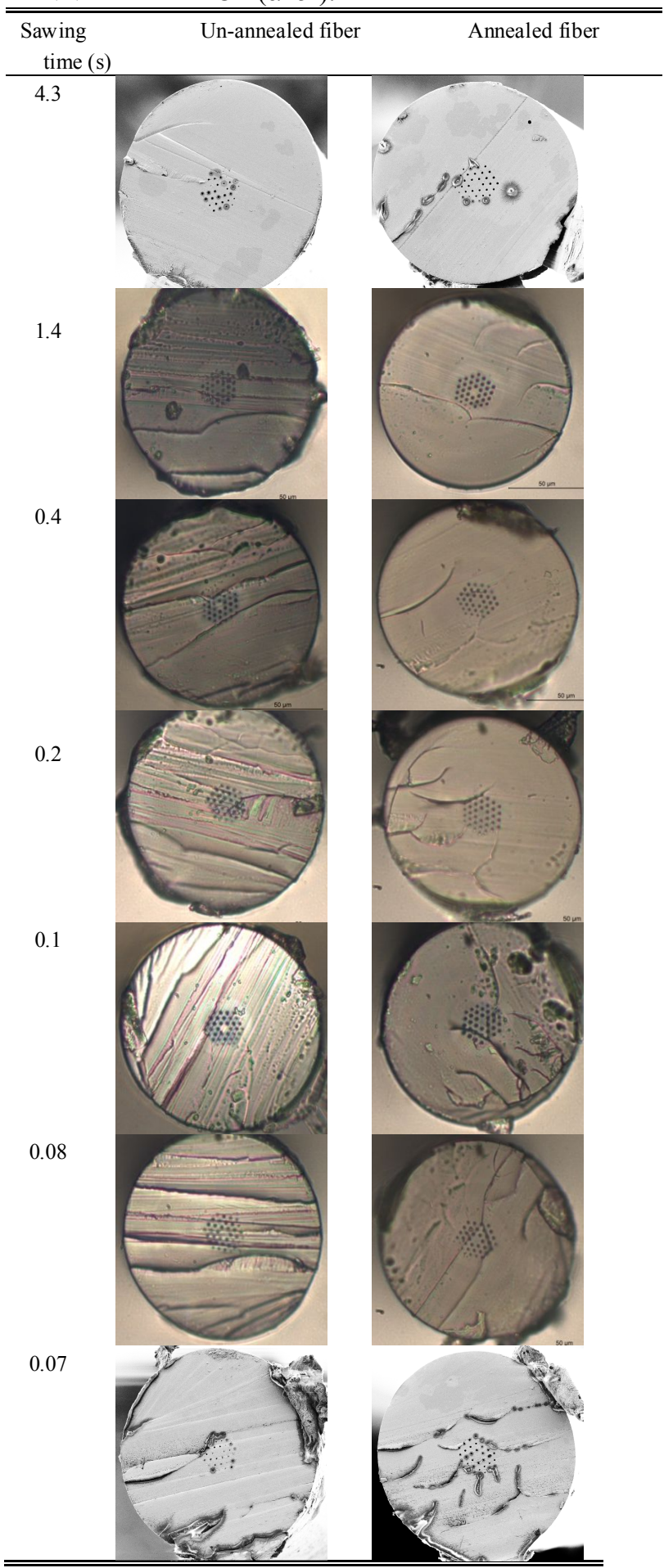

\section{CONCLUSIONS}

In conclusion, we have demonstrated the implementation and testing of the first high quality electrically passive and portable polymer optical fiber cleaver. The device has been satisfactorily characterized by using different microstructured fibers which, in general, are difficult to cut. The role of fiber annealing to improve the quality of cleaving has also been demonstrated.

\section{REFERENCES}

[1] J.C. Knight, T.A. Birks, P.St. Russell, D.M. Atkin “All-silica single-mode optical fiber with photonic crystal cladding” Opt. Lett., 21, 1547, 1996.

[2] R.F. Cregan, B. J. Mangan, J. C. Knight, T. A. Birks, P. St.J. Russell, P. J. Roberts and D. C. Allan, "Single- mode photonic band gap guidance of light in air," Science 285, 1537, 1999.

[3] N.A.Mortense, J.R. Folkenberg, M.D.Nielsen, K.P.Hansen, "Modal cutoff and the V paramenter in photonic crystal fibers" Opt. Lett., 28, 1879, 2003.

[4] J.C.Knight, T.A. Birks, R.F.Cregan, P.St.J. Russell, J.P.Sandro "Large mode area photonic crystal fiber”,Electron. Lett., 34, 1347, 1998.

[5] L.Yan-feng, HU.Ming-lie, C.Lu, W.Ching-yue, "Enhanced nonlinear effects in photonics crystal fibers" Front. Phys. China, 2, 170, 2006.

[6] A.Cerqueira S Jr, "Recent progress and novel applications of photonic crystal fibers" Rep. Prog. Phys., 73, 024401, 2010.

[7] I.T.Monroy, H.P.A.Boom, A.M.J.Koonen, G.D.Khoe, Y.Watanabe, Y.Koike, T.Ishigure, "Data transmission over polymer optical fibers" Opt. Fib. Tech., 9, 159, 2003.

[8] M.A.V.Eijkelenborg, M.Large, A.Argyros, J.Zagari, S.Manos, N.Issa, I.Bassett, S.Fleming, R.McPhedran, C.M.de Sterke,, N.A.P.Nicorovici, "Microstructured polymer optical fiber," Opt. Exp., 9, 319, 2001.

[9] A.Argyros, M.A.V.Eijkelenborg, M.C.J.Large, I.M. Bassett, "Hollow-core microstructured polymer optical fiber" Opt. Lett., 31, 172, 2006.

[10] M.C.J.Large, L.Poladian, G.Barton, M.A.V.Eijkelenborg, "Microstructured polymer optical fibers" chapter 8, Springer, 2008.

[11] G.Giraretta, W.White, M.Wegmuller, T.Onishi, "High-speed (11 Gbit/s) data transmission using perfluorinated graded-index polymer optical fibers for short interconnects (<100)" Phot. Tech. Lett., 12, 347, 2000.

[12] J.Canning, E.Buckley, N.Groothoff, B.Luther-Davies, J.Zagari, "UV laser cleaving of air-polymer structured fiber," Opt. Commun., 202, 139, 2002.

[13] S.H.Law, M.A.V.Eijkelenborg, G.W.Barton, C.Yan, R.Lwin, J.Gan, "Cleaved end-face quality of microstructured polymer optical fibers," Opt. Commun., 265, 513, 2006.

[14] A.Stefani, K.Nielsen, H.K.Rasmussen, O.Bang, "Cleaving of TOPAS and PMMA microstructured polymer optical fibers: core-shift and statistical quality optimization,” Opt. Commun., 285, 1825, 2012.

[15] A.V.Hove, T.Coosemans, B. Dhoedt, P.V.Daele, R.Baets, J.V.Koestsem, L.Van den Torren "Termination of small diameter (125micras) plastic optical fiber for 1x12 Datacommunication" Electronic Components and technology conference, 0-7803-4526-6/98, 1999.

[16] M.V.P.Ghirghi, V.P.Minkovich, A.G.Villegas, "Polymer optical fiber termination with use of liquid nitrogen" Photon.Tech.Lett., 26, 516,2014.

[17] A.Abang, D.J.Webb, "Demountable connection for polymer optical fiber grating sensors" Optical Engineering, 51, 080503-1, 2012.

[18]D.Sáez-Rodríguez, K.Nielsen, O.Bang, D.J.Webb "Simple room temperature method for polymer optical fiber cleaving" J. ligthwave technol., 33, 4712, 2016

[19] I.M.Ward, Mechanical Properties of Solid Polymers. New York, NY, USA: Wiley, 1983.

[20]J.C.Robinson, An introduction to ordinary differential equations. Cambridge University Press, 2003. 